\section{Trellising System and Cane Density Affect Yield and Fruit Quality of Red Raspberry}

\author{
Justine E. Vanden Heuvel, J. Alan Sullivan', and John T.A. Proctor \\ Department of Plant Agriculture, Horticultural Science Division, University \\ of Guelph, Guelph, Ontario, Canada NIG 2W1
}

Additional index words. yield potential, V-trellis, single-sided shift-trellis, hedgerow, Rubus idaeus

\begin{abstract}
Trellising and cane density treatments were applied to vigorous raspberry (Rubus idaeus L.) cv. Titan plants in Southern Ontario to determine their effects on yield, yield potential, and canopy microclimate during the 1997 and 1998 seasons. The trellising treatments compared were hedgerow (control), V-trellis, and single-sided shift-trellis (shift-trellis). Cane densities $\left(9,16,23\right.$, and 30 canes $\left./ \mathrm{m}^{2}\right)$ were established before budbreak each season. The treatments significantly affected yield and yield components. Path analysis indicated that interrelationships among yield components were significantly affected by trellising system. In the second season, plants trained on the V-trellis yielded more than did those in a hedgerow system, while those trained on a shift-trellis had the lowest yield because of a smaller fruiting framework. Fruit quality was lower on the shifttrellis than in the other two systems. These differences were related to light penetration into the three canopies. While an optimum cane density was not found for any system, the maximum cane density $\left(30\right.$ canes $\left./ \mathbf{m}^{2}\right)$ produced the highest yields. Yield potential per cane decreased as cane density increased; however, the increase in cane number compensated for this decrease, resulting in an increase in total yield per unit area. Fruit quality also decreased as cane density increased, but cane density did not affect canopy microclimate.
\end{abstract}

In dense raspberry canopies, the simultaneous existence of both primocanes and floricanes results in strong competition for light between the canes (Wright and Waister, 1982a). This has many implications for productivity, including increased disease incidence because of reduced air circulation, slower drying, and limited penetration of pesticides (Goulart and Demchak, 1993; Stiles, 1994), as well as lower picking efficiency (Stiles, 1995), all of which result in lower yield and yield potential (Cameron et al., 1993). A trellising system is often used to increase exposure to light, which can increase yield (Crandall, 1980; Oydvin, 1986), and to divide the canopy for increased air circulation (Goulart and Demchak, 1993) permitting faster drying and improving picking efficiency (Oydvin, 1986).

The introduction of the single-sided shifttrellis (shift-trellis) into bramble production presents new opportunities in canopy management and harvesting efficiency (Stiles, 1995). The shift-trellis is a dynamic system, in which canes are placed in a horizontal position ini-

\footnotetext{
Received for publication 21 June 1999. Accepted for publication 7 Feb. 2000. This research was supported by the Ontario Ministry of Agriculture, Food, and Rural Affairs, and the Ontario Fruit and Vegetable Growers Association. We thank B Trenwith of Stonehaven Farms for the use of his plant material. This paper is a portion of a thesis submitted by Justine E. Vanden Heuvel. The cost of publishing this paper was defrayed in part by the payment of page charges. Under postal regulations, this paper therefore must be hereby marked advertisement solely to indicate this fact.

${ }^{1}$ To whom requests for reprints should be addressed. E-mail address: asulliva@uoguelph.ca
}

scission, favoring the development of fungal diseases (Stiles, 1994), and fruiting laterals can grow toward the center of the canopy, making harvest difficult.

The fruitfulness of a raspberry planting can be influenced by the density of the canes (Crandall et al., 1974) and competition between canes (Buszard, 1986; Wright and Waister, 1982a). Recommended cane density in Ontario is 10-15 canes/m (Louws, 1996) in the hedgerow system. Cane density per hectare will vary with row spacing, but row widths commonly vary between 30 and $100 \mathrm{~cm}$. Once canes are trellised and competition between vegetative and fruiting canes is reduced, cane densities may increase beyond the current recommendation. To our knowledge, the interaction between trellising system and cane density has not been reported in the literature.

The objectives of this experiment were to: 1) evaluate the yield potential and picking efficiency of three trellising systems; 2) determine the interaction of cane density and trellising system; and 3) determine if incidence of cane disease is affected by trellising system.

\section{Materials and Methods}

Plant material. A 3-year-old commercial planting of the red raspberry, cv. Titan, was used. The planting was located south of Campbellville, Ont., on a slight slope. The plants were established in the field in 1995, and had been trained to a hedgerow system. The canes were vigorous, with an average height and diameter of $137 \mathrm{~cm}$ and $11 \mathrm{~mm}$, respectively, in 1997, and $123 \mathrm{~cm}$ and $9 \mathrm{~mm}$, respectively, in 1998, before treatments began. Prior to beginning this experiment, the incidence of disease in the planting was negligible. Rows were planted on $2.5-\mathrm{m}$ row centers in an eastwest orientation. Two rows in the middle of the planting were chosen for the experiment, as they had the necessary cane densities and were bordered by adjacent guard rows. Two replications were located in each row. Full bloom occurred on about 28 June 1997 and 1 June 1998. Standard management practices for Ontario were followed (Louws, 1996).

Treatments. The experiment was designed as a factorial with three trellising systems and four cane densities. A randomized completeblock design was used with four replicate plots each $2 \mathrm{~m}$ long.

Density treatments were applied at the beginning of May, and were calculated on a $\mathrm{m}^{2}$ basis. Row width was $\approx 65 \mathrm{~cm}$, and therefore linear densities in the row of $6,10,17$, and 23 canes/m were translated into densities of $9,16,23$, and 30 canes $/ \mathrm{m}^{2}$ within the row. The current recommended cane density in Ontario is 10-15 canes/m (Louws, 1996).

Trellising treatments consisted of the hedgerow, the V-trellis, and the single-sided shift-trellis. Canes in the shift-trellis treatments were placed in the horizontal position prior to budbreak, then reorientated on 2 July 1997, following full bloom, according to Stiles's (1995) recommendations for blackberry. In 1998, the shift-trellis was shifted on 21 May, at the beginning of bloom. The V- 
trellis and the hedgerow treatments were applied shortly after the beginning of budbreak, when laterals were $<10 \mathrm{~mm}$ long. Trellising systems remained in place until canes were removed for growth analysis after harvest. Primocanes were allowed to grow freely within the $0.65-\mathrm{m}$ row width.

Yield. Yield was measured on a $1.0-\mathrm{m}$ length of row in the center of each 2-m plot. Fruit were harvested on alternate days. Quality of fruit was high and all fruit were considered marketable. Total weight was measured at each harvest, and average fruit weight was calculated as sample weight ( 1 pint $\approx 0.55 \mathrm{~L}$ ) divided by fruit number per sample.

Growth analysis. Following harvest, six floricanes were removed at random from the center meter of each plot for growth analysis. Each fruiting cane was cut at soil level and then divided into three equal lengths (i.e., upper, center, lower) to determine lateral number, total lateral length, node number, and percentage of budbreak for each section. Percentage of budbreak was determined by dividing lateral number by node number in each section of the cane.

Disease rating. Disease incidence was estimated during growth analysis by counting the number of disease lesions that penetrated through the bark between 60 and $100 \mathrm{~cm}$ on one side of the cane $\left(180^{\circ}\right)$. Lesions were not classified as to causal organism.

Fruiting zone temperature and duration of leaf wetness. To determine the effects of trellising and cane density on microclimate within the canopy, temperature and cane wetness were monitored in one replication of the experiment between 6 June and 22 Nov. 1997, and 1 June and 15 Aug. 1998. Temperatures were measured with a LI-COR Soil Thermistor (model 1000-15) connected to a LI-COR LI-1000 datalogger (LI-COR, Lincoln, Nebr.). Cane wetness was approximated using a cylindrical wetness sensor (length $=18$ $\mathrm{cm}$, diameter $=1 \mathrm{~cm}$ ) made of plexiglass with a $2.5-\mathrm{cm}$ sensing length. Sensors were placed in the center of the canopy at a height of $80 \mathrm{~cm}$, with the exception of the V-trellis, where sensors were placed in the north fruiting wall. Total duration of wetting for each rain incident, and minimum, maximum, and average temperature over each $24-\mathrm{h}$ period from noon to noon were calculated for each treatment.

Light penetration into the canopy. The photosynthetically active radiation [photosynthetic photon flux density $(P P F D)$ ] was measured in the center of the canopy at four heights: ground level, $50 \mathrm{~cm}$ aboveground, $100 \mathrm{~cm}$ aboveground, and above the canopy. Percentage of full sunlight penetrating the canopy was calculated at each height. In 1998, measurements were taken during canopy development on 7 May and 14 May.

Radiation measurements were taken with a 1-m long LI-COR Line Quantum sensor (model 191SA) and Quantum Sensor (model 190SA), connected to a LI-COR LI-1000 datalogger. The line sensor was placed at the various heights in the canopy, while the quantum sensor was placed above the canopy to determine the intensity of full sunlight. Both sensors recorded radiation over a 5-min period before being moved to the next location. Light levels at each position were determined as a percentage of full sunlight above the canopy. All light measurements were taken on cloudless days.

Fruit quality. Fruit quality in each plot was determined on two dates in 1997, and on one date in 1998. One-pint $(\approx 0.55 \mathrm{~L})$ samples from plots were stored in plastic bags in a chest freezer until analysis. Berries were crushed and the juice was strained and analyzed for soluble solids, $\mathrm{pH}$, and titratable acidity. Percentage of soluble solids of sampled berries was determined using a hand-held refractometer $(0 \%$ to $25 \%$; Fisher Scientific, Nepean, Ont). The $\mathrm{pH}$ of the juice was determined with a temperature-compensated $\mathrm{pH}$ meter (Waterproof pH Testr 1, Cole-Palmer, Vernon Hills, Ill.). Titratable acidity was determined by mixing $10 \mathrm{~mL}$ of juice with $90 \mathrm{~mL}$ of distilled water and titrating with $0.1 \mathrm{~N} \mathrm{NaOH}$ to a $\mathrm{pH}$ of 7.0, according to the protocol of Perkins-Veazie and Nonnecke (1992). Titratable acidity was then calculated as amount of citric acid (g) in $100 \mathrm{~mL}$ of juice.

Picking efficiency. Picking efficiency was measured on 25 and 31 July, and on 6 Aug. in 1997, and on 13 and 17 July in 1998. Two people were timed as they picked each 1-m plot. Total fruit weight per plot for that date was divided by the time required for picking, in order to calculate a picking efficiency $\left(\mathrm{kg} \cdot \mathrm{h}^{-1}\right)$ for each treatment.

Analysis of data. Analysis of variance, including least square means and $95 \%$ confidence limits, were completed using the General Linear Model technique in SAS (SAS Institute, Cary, N.C.). Normality of data was tested using the Shapiro-Wilk W-test.

Path coefficient analysis (Sokal and Rohlf, 1995) was used to determine relationships among yield components. Data were combined across years, transformed logarithmically for linearity, and standardized to a mean of zero. Path diagrams were based on multiple regression equations to reflect the dependent structure of the components.

\section{Results}

Early in the season light attenuated more quickly in the hedgerow than in the V-trellis at all cane densities (data not shown). Once the primocanes had reached a height of $\approx 70 \mathrm{~cm}$, light penetration into the canopy was similar in both trellises, as the plants had filled the area between outside wires.

Yield. Trellising system had no overall effect on yield per $\mathrm{m}^{2}$ in 1997. In 1998, yield for the shift and V-trellises was $\approx 59 \%$ and
$119 \%$ of that of the hedgerow, respectively (Table 1). Cane density had a significant linear effect on yield per $\mathrm{m}^{2}$ in both years (1997: $r^{2}=$ $0.52, \mathrm{~b}=160.04)\left(1998: r^{2}=0.22, \mathrm{~b}=136.25\right)$. Yield response to increasing cane density for the V-trellis, hedgerow, and shift-trellis was 162,201 , and $66 \mathrm{~g}$ per cane per $\mathrm{m}^{2}$, respectively, in 1998 (Fig. 1A). The yield contributed by each additional cane with increasing cane density resulted in an increase in yield per $\mathrm{m}^{2}$. Yield per cane declined linearly within each trellising system with increasing cane density (Fig. 1B).

Fruit number. Increases in yield in both years were accompanied by a concomitant decrease in fruit number per cane, but an increase in fruit number per $\mathrm{m}^{2}$. Differences were particularly evident in the second year, when plants trained to the shift and V-trellises produced $62 \%$ and $123 \%$ as many fruits per cane, and $58 \%$ and $120 \%$ as many fruits per $\mathrm{m}^{2}$, respectively, as did those grown as hedgerows (Table 1; Fig. 1C). Number of fruit per $\mathrm{m}^{2}$ increased in a positive and linear manner as cane density increased (Fig. 1C). For each unit increase in cane density, however, fruit per cane decreased by 56,49 , and 21 fruits for the hedgerow, V-trellis, and shift-trellis, respectively (data not shown).

Fruit size. Average fruit size was not affected by trellising system (Table 1); however, a negative, linear decrease in fruit weight was observed in all trellising systems as cane density increased (Fig. 2).

Growth analysis. On the lower portion of the cane, the shift and V-trellis produced fewer fruitful nodes than the hedgerow in 1997 (data not shown). In 1998, the V-trellis had a lower percentage of fruitful nodes (Table 2) than did the hedgerow and the shift-trellis.

On the center portion of the cane, the shifttrellis had a lower percentage of fruitful nodes, fewer laterals, and more nodes per cane than did the hedgerow in 1998 (Table 2), whereas the $\mathrm{V}$-trellis produced similar characteristics to the hedgerow with the exception of lateral length. Number of fruitful nodes $\left(r^{2}=0.13\right.$, $\mathrm{b}=-0.06)$ and total lateral length $\left(r^{2}=0.21\right.$, $\mathrm{b}=-2.96)$ each decreased linearly as cane density increased.

On the upper portion of the cane, the shift-trellis produced fewer fruitful nodes, and fewer and shorter laterals than did the hedgerow in 1998, whereas these characteristics were similar in the V-trellis and hedgerow systems (Table 2).

Path coefficient analysis. The interrelationships among yield components in the V-trellis differed from those in the other two systems. In the hedgerow and shift-trellis, cane density had

Table 1. Main effects of trellising system on yield, fruit size, fruit number per cane, and fruit number per $\mathrm{m}^{2}$ of 'Titan' red raspberry in 2 years.

\begin{tabular}{|c|c|c|c|c|c|c|c|c|}
\hline \multirow[b]{2}{*}{ System } & \multicolumn{2}{|c|}{ Yield $\left(\mathrm{kg} \cdot \mathrm{m}^{-2}\right)$} & \multicolumn{2}{|c|}{ Fruit size $(\mathrm{g})$} & \multicolumn{2}{|c|}{ Fruit no./cane } & \multicolumn{2}{|c|}{ Fruit no. $/ \mathrm{m}^{2}$} \\
\hline & 1997 & 1998 & 1997 & 1998 & 1997 & 1998 & 1997 & 1998 \\
\hline Hedgerow & 2.8 & $6.1 b^{z}$ & 3.2 & 3.2 & $53 \mathrm{a}$ & $83 \mathrm{~b}$ & $1143 \mathrm{a}$ & $1509 \mathrm{~b}$ \\
\hline Shift & 2.0 & $3.6 \mathrm{c}$ & 3.3 & 3.3 & $37 \mathrm{~b}$ & $51 \mathrm{c}$ & $723 \mathrm{~b}$ & $875 \mathrm{c}$ \\
\hline V-trellis & 3.0 & $7.3 \mathrm{a}$ & 3.3 & 3.3 & $56 a$ & $103 \mathrm{a}$ & $1144 \mathrm{a}$ & $1817 \mathrm{a}$ \\
\hline$P$ & 0.239 & $<0.001$ & 0.208 & 0.194 & 0.014 & $<0.001$ & 0.005 & 0.016 \\
\hline
\end{tabular}

${ }^{\mathrm{z}}$ Mean separation within columns by $t$ test, $P \leq 0.05$.

Mean separation within columns by $t$ test, $P \leq 0.05$. 

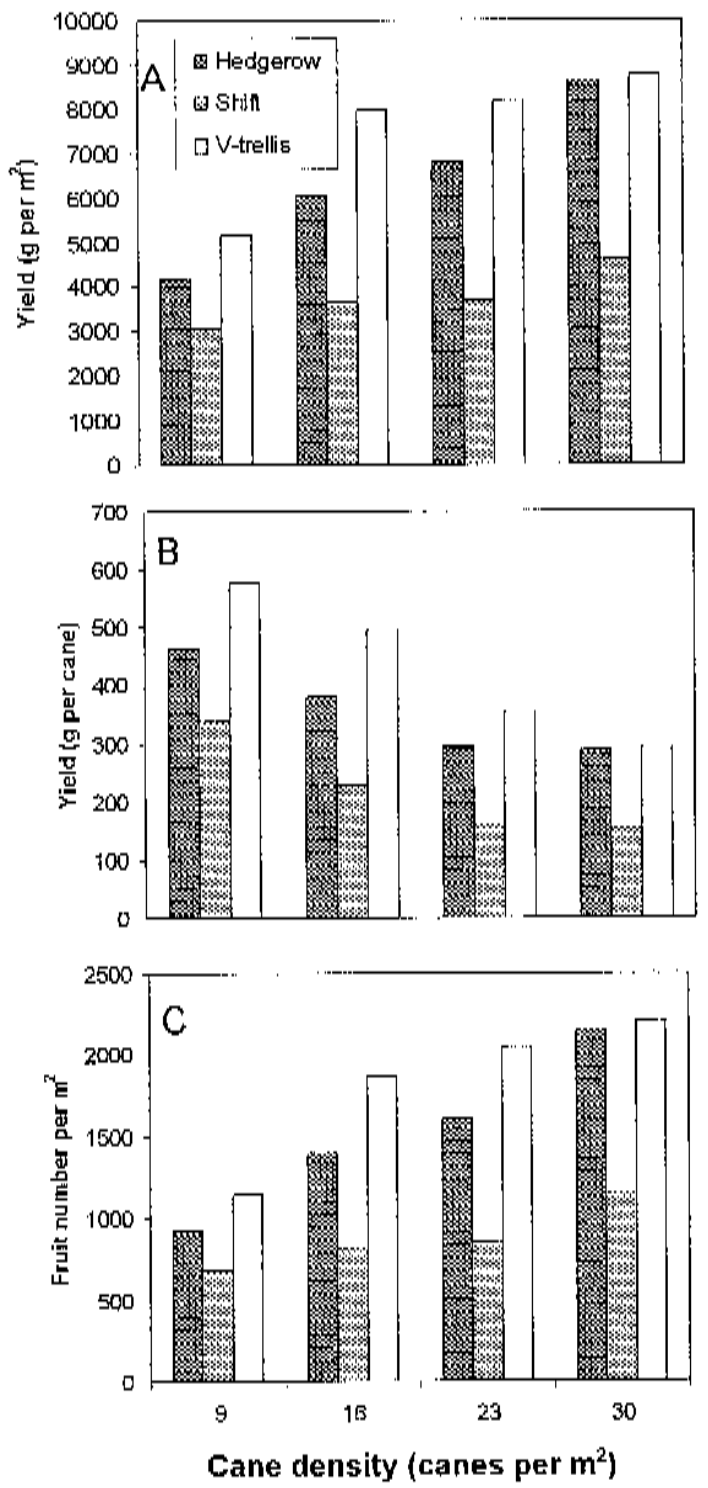

Fig. 1. Effects of trellising system and cane density on $(\mathbf{A})$ : yield per $\mathrm{m}^{2}$ ( $\mathrm{SE}=575$ for all bars except $\mathrm{V}$-trellis at 30 canes $/ \mathrm{m}^{2}$ where $\left.\mathrm{SE}=664\right),(\mathbf{B})$ yield per cane $\left(\mathrm{SE}=33\right.$ for all bars except V-trellis at 30 canes $/ \mathrm{m}^{2}$ where $\mathrm{SE}=38)$, and $(\mathbf{C})$ fruit number per $\mathrm{m}^{2}\left(\mathrm{SE}=133\right.$ for all bars except V-trellis at 30 canes $/ \mathrm{m}^{2}$ where $\mathrm{SE}=154)$ of 'Titan' red raspberry in 1998.

the greatest effect on total yield(Fig. 2A and B), while in the $\mathrm{V}$-trellis, cane density had a more significant effect on fruit size than on total yield (Fig. 2C). Fruit size did not affect yield in the Vtrellis, but did affect yield in the other two systems. Number of laterals per cane had no significant effect on either fruit per lateral or total yield in the V-trellis, but significantly affected yield in both hedgerow and shift-canopies (Fig. $2 \mathrm{~A}$ and B). The number of fruit per lateral had no effect on fruit weight in the $\mathrm{V}$ trellis, but had a significant and negative effect in the other two systems.

While cane density had a significant negative relationship with number of fruit per lateral in the shift-trellis (Fig. 2B), there was no significant relationship between those two components in either the hedgerow or the $\mathrm{V}$-trellis. In the hedgerow, number of laterals per cane was not affected by cane density, but was negatively affected in both the shift-trellis and the V-trellis.
Disease. Incidence of disease was not significantly affected by trellising system or cane density in either 1997 or 1998 , although disease levels in the planting were extremely low at the beginning of the experiment.

Canopy microclimate. No significant differences were found in air temperature or drying time between trellising systems or cane densities.

Fruit quality. Generally, quality of fruit from the V-trellis was either comparable with or higher than did that of fruit from the hedgerow. The shift-trellis produced lower quality fruit than did the hedgerow on two of three sampling dates (Table 3). Increasing cane density reduced soluble solids $\left(r^{2}=0.08\right.$, $\mathrm{b}=-0.023)$.

Picking efficiency. Significant differences in picking efficiency were found on only two of the five dates of measurement over 2 years (data not shown). On 31 July 1997 the shifttrellis was only $5 \%$ more efficient to pick than was the hedgerow $\left(2.8 \mathrm{~kg} \cdot \mathrm{h}^{-1}\right)$, while the $\mathrm{V}$ trellis was $3 \%$ more efficient. However, 1 week later, the shift-trellis and $\mathrm{V}$-trellis were $-4 \%$ and $+4 \%$ as efficient to pick, respectively, as was the hedgerow. The width of the row was $65 \mathrm{~cm}$, requiring that canes on the opposite side of the fruiting wall in the shifttrellis be bent at an angle $>45^{\circ}$ in order to be tied onto the wire when canes were shifted. Laterals from those canes terminated in the center of the trellising system, making the fruit very difficult to reach. In contrast, fruit from the V-trellis were located primarily at the edges of the canopy.

\section{Discussion}

The greater yield of the V-trellis and hedgerow vs. the shift-trellis can be attributed to an increased number of fruits per cane, similar to the findings of Nehrbas and Pritts (1988) in their work with trellising systems. Several other researchers (Braun and Garth, 1984; Crandall et al., 1974, 1980; Swartz et al., 1984; Waister and Barritt, 1980; Wright and Waister, 1982b) have also attributed yield increases to greater fruit number. In raspberry, primocane dry weight increases steadily until the peak of fruiting (Fernandez and Pritts, 1994), indicating that carbohydrate stress may lead to floral abortion (Kinet, 1977), which reduces fruit number and hence yield. The greater light penetration in the $\mathrm{V}$-trellis would reduce carbohydrate stress, allowing the plant to maintain fruit number.

Trellising can improve vegetative growth, thereby enhancing yield potential. The canes in the V-trellis system had significantly longer laterals on the center portion than did those in the hedgerow, and had a slightly higher percentage of fruitful nodes on the center portion of the cane, as well as a trend toward more and longer laterals on the upper third of the cane. These growth advantages led to a larger potential fruiting area in the V-trellis than in the hedgerow because of higher light levels for both the primocanes and floricanes in the earlier part of the season. The additional vegetative growth on these canes that were orientated to optimize light distribution may have produced additional carbohydrates for the plant that contributed to higher yields.

The yield advantage of the V-trellis over the hedgerow was low relative to previous comparisons (Goulart and Demchak, 1993; Nehrbas and Pritts, 1988), due in part to the extreme vigor of the plants used in this experiment. Early in the season, the canopy on the V-trellis had completely filled the allotted space, and looked very similar to that of the hedgerow. The yield increase in the V-trellis, therefore, must have been due to increased light penetration at the beginning of the season. Following the last date of light measurement (14 May), the canopies were extremely dense, and a light meter could not be inserted without causing damage to the plants and equipment. Unfortunately, light measurements could not be taken in the upright canopy position of the shift-trellis because of the density of the laterals. 

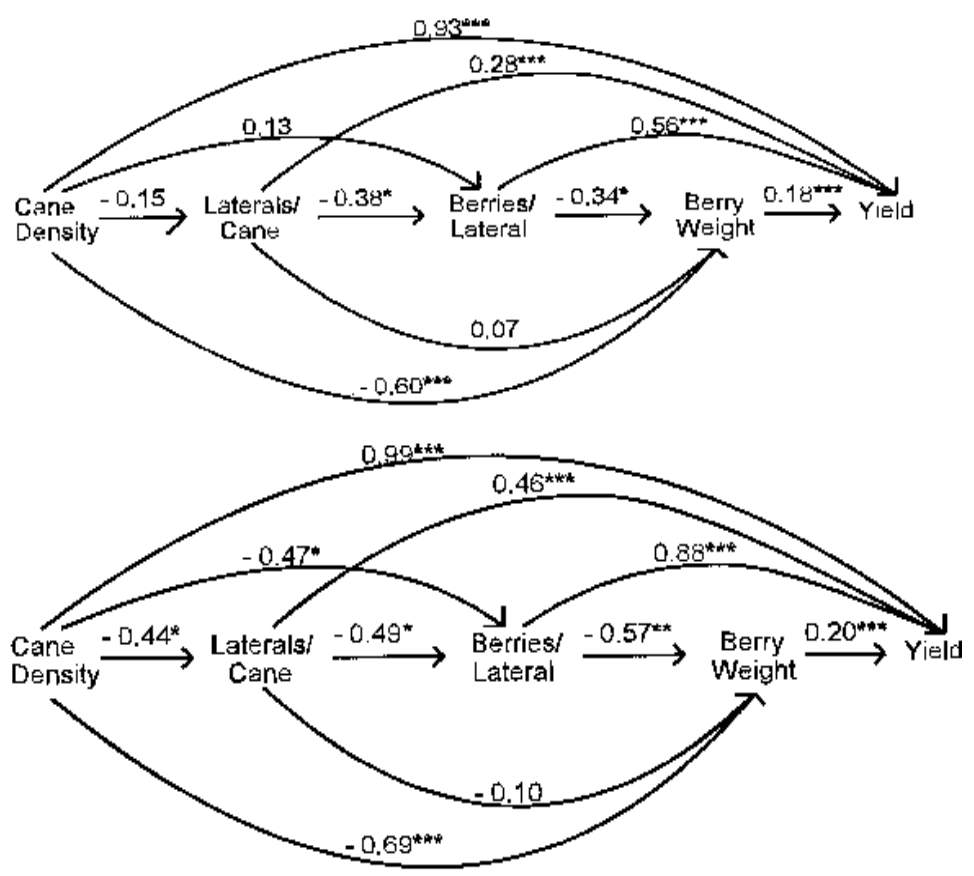

(C)

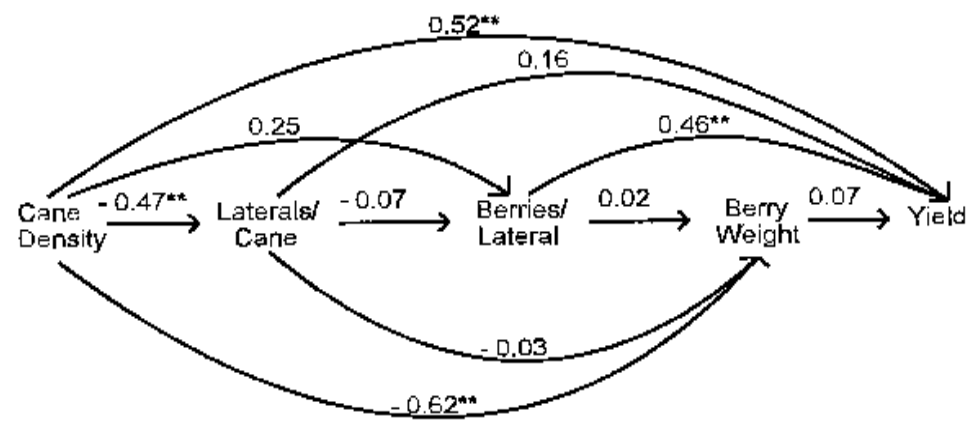

Fig. 2. Diagrammatic representation of the interrelationships among yield components for 'Titan' red raspberry as determined from path analysis. (A) Hedgerow system; (B) Shift-trellis system; (C) Vtrellis system. ${ }^{* * * * * * *}$ Significant at $P \leq 0.05,0.01$, or 0.001 , respectively.

Generally, at the lower cane densities, the $\mathrm{V}$-trellis allowed light to penetrate farther into the canopy than did the hedgerow, which would have favored photosynthesis. The Vtrellis had higher light levels than did the hedgerow throughout the canopy above 50 $\mathrm{cm}$, or $1 \mathrm{~m}$ at higher densities.

The lower yield produced on the shifttrellis than on the V-trellis and hedgerow can be attributed in part to low light levels observed in the shift-trellis prior to shifting. When the canes were laid out horizontally in the spring, about half of the nodes faced downward, and received only minimal light. As a result of the horizontal orientation, only $59 \%$ of the nodes on the center portion of the cane formed laterals, vs. $75 \%$ for the hedgerow and $79 \%$ for the $V$-trellis. On the upper third of the cane, only $32 \%$ of nodes formed laterals, vs. $45 \%$ and $46 \%$ for the hedgerow and $\mathrm{V}$-trellis, respectively. The canes in the shifttrellis produced fewer laterals on the center and upper portions of the cane, decreasing yield potential on the most productive portion (Dale, 1989). Previous research has pro- when the laterals were broken during the shifting phase. The problem was only partially overcome by shifting the trellis at the beginning rather than at the end of bloom in the second year of the study. Primocane interference is a serious limitation to the use of the shift-trellis for raspberry production because of the prolific production of primocanes. While primocane suppression may partially address this limitation, the suppression of the first flush of primocanes in Eastern Canada caused yield reductions of $15 \%$ to $35 \%$ (Sullivan and Dale, 1989). The problem of primocane interference may also be addressed by using a biennial system of cane management (Dale, 1989). However, the high cost of the framework may prohibit the use of the alternate-year system where economic return is lower than for the hedgerow.

Path coefficient analysis indicated that the V-trellis generally had fewer negative relationships among yield components than did the other two systems. The influence of cane density on total yield in the V-trellis was smaller than in the other two systems and indicated that the response of yield components to increasing cane density differed among systems. As cane density increased in the hedgerow and the shift-trellis, yield potential per cane decreased at a greater rate than in the V-trellis. This response explains why yield was less subject to increased cane density in the V-trellis than in other systems. The number of fruit per lateral did not have a negative effect on fruit size in the $\mathrm{V}$-trellis, and changes in fruit size and number of laterals per cane had no effect on yield. This characteristic of plants in the V-trellis suggests that high yield can be achieved even when environmental conditions greatly affect individual yield components (Wright and Waister, 1982).

The shift-trellis was designed to improve picking efficiency, but efficiency was better on only one out of five dates. The single-sided fruiting wall on the shift-trellis increased picking efficiency $(5 \%)$ only during maximum fruit load. Generally, differences between picking efficiencies were nonsignificant during most of the fruiting period.

Increased fruit quality is related to improved light environment in the trellising system (Palmer et al., 1987; Swartz et al., 1984). In 1997, probably because of low levels of light reaching the inner fruit as they matured, the shift-trellis produced fruit with lower sugar levels and higher $\mathrm{pH}$ than did the $\mathrm{V}$-trellis. The structure of the shift-trellis resulted in most berries growing in the shade, which reduced sunscald but also reduced berry quality (Swartz et al., 1984). In 1997, many primocanes shaded the fruiting wall, decreasing light to the fruiting canes and reducing soluble solids (Swartz et al., 1984). These differences in fruit quality between the shift-trellis and the other trellising systems were not observed in 1998 because of decreased primocane interference resulting from an earlier shift, as well as the removal of many primocanes from the front wall of the canopy to facilitate management.

No differences in leaf drying time or canopy temperature were found among trellising sys- 
Table 2. Effects of trellising system on characteristics of 'Titan' red raspberry floricanes in 1998 .

\begin{tabular}{|c|c|c|c|c|}
\hline System & $\begin{array}{c}\text { Lateral } \\
\text { length }(\mathrm{cm})\end{array}$ & $\begin{array}{c}\text { Lateral } \\
\text { no. }\end{array}$ & $\begin{array}{c}\text { Node } \\
\text { no. }\end{array}$ & $\begin{array}{c}\% \text { Fruitful } \\
\text { nodes }\end{array}$ \\
\hline \multicolumn{5}{|c|}{ Lower portion of cane } \\
\hline Hedgerow & 126 & $3.0 \mathrm{a}^{\mathrm{z}}$ & 8.3 & $36.6 \mathrm{a}$ \\
\hline Shift & 114 & $3.2 \mathrm{a}$ & 8.2 & $38.6 \mathrm{a}$ \\
\hline V-trellis & 115 & $2.6 \mathrm{~b}$ & 8.6 & $31.2 \mathrm{~b}$ \\
\hline$P$ & 0.405 & 0.032 & 0.624 & 0.020 \\
\hline \multicolumn{5}{|c|}{ Center portion of cane } \\
\hline Hedgerow & $234 \mathrm{~b}$ & $6.4 \mathrm{a}$ & $8.5 \mathrm{~b}$ & $74.6 \mathrm{a}$ \\
\hline Shift & $205 \mathrm{~b}$ & $5.8 \mathrm{~b}$ & $9.7 \mathrm{a}$ & $58.7 \mathrm{~b}$ \\
\hline V-trellis & $258 \mathrm{a}$ & $6.7 \mathrm{a}$ & $8.5 \mathrm{~b}$ & $79.1 \mathrm{a}$ \\
\hline$P$ & 0.006 & 0.020 & 0.001 & $<0.001$ \\
\hline \multicolumn{5}{|c|}{ Upper portion of cane } \\
\hline Hedgerow & $186 \mathrm{a}$ & $8.6 \mathrm{a}$ & $19.1 \mathrm{~b}$ & $45.1 \mathrm{a}$ \\
\hline Shift & $171 \mathrm{~b}$ & $6.6 \mathrm{~b}$ & $20.6 \mathrm{a}$ & $33.7 \mathrm{~b}$ \\
\hline V-trellis & $208 \mathrm{a}$ & $9.1 \mathrm{a}$ & $19.4 \mathrm{~b}$ & $45.8 \mathrm{a}$ \\
\hline$P$ & 0.033 & 0.007 & 0.002 & $<0.001$ \\
\hline
\end{tabular}

Table 3. Effect of trellising system on soluble solids (SS), pH, and titratable acidity (TA) of 'Titan' red raspberries on three harvest dates.

\begin{tabular}{|c|c|c|c|c|c|c|c|c|c|}
\hline \multirow[b]{2}{*}{ System } & \multicolumn{3}{|c|}{ 22 July 1997} & \multicolumn{3}{|c|}{6 Aug. 1997} & \multicolumn{3}{|c|}{11 July 1998} \\
\hline & $\begin{array}{c}\mathrm{SS} \\
\left({ }^{\circ} \text { Brix }\right)\end{array}$ & $\mathrm{pH}$ & $\begin{array}{c}\text { TA } \\
(\mathrm{g} / 100 \mathrm{~mL})\end{array}$ & $\begin{array}{c}\text { SS } \\
\left({ }^{\circ} \text { Brix }\right)\end{array}$ & $\mathrm{pH}$ & $\begin{array}{c}\text { TA } \\
(\mathrm{g} / 100 \mathrm{~mL})\end{array}$ & $\begin{array}{c}\mathrm{SS} \\
\left({ }^{\circ} \text { Brix }\right)\end{array}$ & $\mathrm{pH}$ & $\begin{array}{c}\text { TA } \\
(\mathrm{g} / 100 \mathrm{~mL})\end{array}$ \\
\hline Hedgerow & $4.7 b^{z}$ & $3.9 \mathrm{c}$ & 2.0 & $8.5 \mathrm{a}$ & 3.1 & 1.5 & $9.0 \mathrm{a}$ & $4.0 \mathrm{c}$ & 2.0 \\
\hline Shift & $5.0 \mathrm{~b}$ & $3.4 \mathrm{~b}$ & 2.0 & $7.4 \mathrm{~b}$ & 3.1 & 1.6 & $8.3 \mathrm{~b}$ & $3.5 \mathrm{~b}$ & 2.1 \\
\hline V-trellis & $5.7 \mathrm{a}$ & $2.9 \mathrm{a}$ & 2.0 & $8.5 \mathrm{a}$ & 3.0 & 1.6 & $9.0 \mathrm{a}$ & $2.9 \mathrm{a}$ & 2.0 \\
\hline$P$ & 0.006 & 0.020 & 0.675 & $<0.001$ & 0.380 & 0.386 & 0.002 & 0.005 & 0.519 \\
\hline
\end{tabular}

${ }^{\mathrm{z}}$ Mean separation within columns by $t$ test, $P \leq 0.05$.

tems or cane densities in either 1997 or 1998. Incidence of disease was also unaffected by trellising system and cane density. This planting had very low levels of disease prior to beginning the experiment, and intensive control measures continued over the course of this research. Increased cane density contributes to high disease load in raspberries (Goulart and Demchak, 1993) because lack of air circulation limits drying. However, in this study with good disease management practices, disease pressures could be minimized even at high cane densities. Increasing disease incidence with higher cane densities could be expected in management systems with minimal pesticide usage.

Our data contradict the current recommendation for cane density of 10-15 canes per $m$ of row in the hedgerow system (note that no row width is specified) (Louws, 1986), and an optimal cane density was not found for any of the trellising systems in this study (Fig. 1). However, as density increased in 1998, several important components of yield decreased, including fruit weight, lateral number, and center cane bud emergence (with the exception of the hedgerow system, where total lateral number on the center portion of the cane increased as density increased). As cane density increased, canes in all systems had smaller fruit, and fewer fruits per cane on fewer and smaller laterals, probably because of reduced light penetration. However, yield did increase because the increase in fruit number per $\mathrm{m}^{2}$ of row as cane density increased more than compensated for decreases in the other yield components. Other researchers (Crandall et al., 1974, 1980; Oydvin,
1980) have also found that increased density increased yield; however, densities studied were lower than the highest density in this experiment. While Dale (1989) suggested that a minimum cane density for optimization of yield exists independent of trellising system, the decrease in additional yield response of the shift-trellis from 23 to 30 canes $/ \mathrm{m}^{2}$ suggests otherwise. Our data suggest that cane density can be increased to maximize yield and yield components in some systems.

The use of the V-trellis increased yield and yield potential in 'Titan' red raspberry by increasing light penetration into the canopy, while the shift-trellis decreased yield, yield potential, and fruit quality, and had no consistent effect on picking efficiency. The shifttrellis is not recommended for use on red raspberries, given its performance and inherent management difficulties. These results lead us to conclude that the full potential of raspberry plantings in the Northeast are not being realized because of low cane densities and the use of the hedgerow system. The use of the V-trellis, combined with higher cane densities, should increase the yield of such plantings.

\section{Literature Cited}

Braun, J.W. and J.K.L. Garth. 1984. Intracane yield compensation in the red raspberry. $\mathrm{J}$. Amer. Soc. Hort. Sci. 109:526-530.

Buszard, D.J.I. 1986. The effect of management system on winter survival and yield of raspberries in Quebec. Acta Hort. 183:175-181.

Cameron, J.S., S.F. Klauer, and C. Chen. 1993. Developmental and environmental influences on the photosynthetic biology of red raspberry (Rubus idaeus L.). Acta Hort. 352:113-121.

Crandall, P.C. 1980. Twenty years of red raspberry research in southwestern Washington state. Acta Hort. 112:53-58.

Crandall, P.C., D.F. Allmendinger, J.D. Chamberlain, and K.A. Biderbost. 1974. Influence of cane number and diameter, irrigation, and carbohydrate reserves on the fruit number of red raspberries. J. Amer. Soc. Hort. Sci. 99:524526

Crandall, P.C., J.D. Chamberlain, and J.K.L. Garth. 1980. The effects of chemical primocane suppression on growth, yield and chemical composition of red raspberries. J. Amer. Soc. Hort. Sci. 105:194-196.

Dale, A. 1989. Productivity in red raspberries. Hort. Rev. 11:185-228.

Fernandez, G.E. and M.P. Pritts. 1994. Growth, carbon acquisition, and source-sink relationships in 'Titan' red raspberry. J. Amer. Soc. Hort. Sci. 119:1163-1168.

Galletta, G.J. and D.G. Himelrick (eds.). 1989. Small fruit crop management. Prentice-Hall, Englewood Cliffs, N.J.

Goulart, B.L. and K. Demchak. 1993. Physiological responses of "T", "V" and hedgerow trained red and black raspberries (Rubus idaeus L. and R. occidentalis L.) Acta Hort. 352:159-165.

Kinet, J. 1977. Effect of light conditions on the development of the inflorescence in tomato. Scientia Hort. 6:15-26.

Louws, F.J. 1996. Growing red raspberries in Ontario. Ont. Min. of Agr., Food, and Rural Affairs, Pub. 105. Queens Printer for Ontario, Toronto.

Nehrbas, S.R. and M.P. Pritts. 1988. Effect of training system on performance of hand-harvested summer-bearing raspberries. HortScience 23:126-127.

Odyvin, J. 1986. The Gjerde method for training raspberries. Effects of increasing cane number and cane height. Acta Hort. 183:173-174.

Palmer, J.W., J.E. Jackson, and D.C. Ferree. 1987. Light interception and distribution in horizontal and vertical canopies of red raspberries. J. Hort. Sci. 62:493-499.

Perkins-Veazie, P. and G. Nonnecke. 1992. Physiological changes during ripening of raspberry fruit. HortScience 27:331-333.

Sokal, R.R. and F.J. Rohlf. 1995. Biometry: The principles and practice of statistics in biological research. Freeman, New York.

Stiles, H.D. 1989. Importance of shifting the wires in a $\mathrm{V}$-trellis for raspberries. HortScience 24:221. (Abstr.)

Stiles, H.D. 1994. One-sided shift trellising addresses harvest, pest management and cultural problems in Rubus. HortScience 25:852. (Abstr.)

Stiles, H.D. 1995. Shift-trellises for better management of brambles (Rubus cvs.). Virginia Agr. Expt. Sta., Bul. 95-2. Blacksburg.

Sullivan, J.A. and A. Dale. 1989. Intensive management of red raspberry in eastern Canada. Acta Hort. 262:405-410.

Swartz, H.J., S.E. Gray, L.W. Douglass, E. Durner, C.S. Walsh, and G.J. Galletta. 1984. The effect of a divided canopy trellis design on thornless blackberry. HortScience 19:533-535.

Waister, P.D. and B.H. Barritt. 1980. Compensation in fruit numbers following loss of lateral buds in the red raspberry. Hort. Res. 20:25-31.

Wright, C.J. and P.D. Waister. 1982a. Withinplant competition in the red raspberry. I. Primocane growth. J. Hort. Sci. 57:437-442.

Wright, C.J. and P.D. Waister. 1982b. Within plant competition in the red raspberry. II. Fruiting cane growth. J. Hort. Sci. 57:443-448. 